\title{
Inhibition of pitting corrosion of AISI 420 (40X13) stainless steel in low-mineralized water by sulphate ions
}

\author{
A.I. Sherbakov, * V.N. Dorofeeva, I.G. Korosteleva, I.V. Kasatkina, \\ L.P. Kornienko and V.E. Kasatkin
}

A.N. Frumkin Institute of Physical Chemistry and Electrochemistry, Russian Academy of Sciences, Leninsky pr. 31, 119071 Moscow, Russian Federation

*E-mail: scherbakov@ipc.rssi.ru

\begin{abstract}
Peculiarities of the pitting corrosion occurrence on AISI 420 (40X13) ferritic stainless steel in low-mineralized water with a composition close to river and tap water are considered. Using the potentiodynamic polarization curves measurements $(0.1 \mathrm{mV} / \mathrm{s})$, the dependences of the pitting potentials on the chloride concentration were obtained, as well as in the presence of sulfate and carbonate ions in a solution. In a certain area of concentrations, the dependence of pitting formation potentials on the logarithm of chloride ions concentration in the electrolyte has been found. An insignificant effect of bicarbonate on pitting corrosion of ferritic stainless steel was discovered. On the contrary, the presence of sulfate ions in solution together with chlorides shifts the pitting potential to more positive values. Their inhibitory effect is the stronger, the lower the concentration of the initial chloride in the aqueous medium. Moreover, the repassivation potential is practically independent of the sulfate concentration. It has been found that the maximum safe chloride concentration for solutions containing 50 and $100 \mathrm{mg} / \mathrm{L}\left[\mathrm{SO}_{4}^{2-}\right.$ ]


greater than in the case of pure chloride solutions without additives. This dependence indicates the existence of a thermodynamic adsorption equilibrium in the case of competing adsorption of chloride and sulfate on the oxide surface. A significant part of the researches are devoted to the inhibition of pitting corrosion of structural alloys by organic inhibitors [1-4]. However, inorganic anions can act as inhibitors for stainless steels [5]. In the current research, the possibility of neutralizing of chloride ions negative effects on pitting corrosion by other components of river water, for example, sulfate and carbonate ions, has been studied.
\end{abstract}

Key words: pitting corrosion, AISI 420 (40X13) steel, low-mineralized water.

Received: March 3, 2020. Published: April 14, 2020

doi: $\underline{10.17675 / 2305-6894-2020-9-2-7}$

AISI 420 stainless ferritic steels are widely employed in various fields, for example, used as a material for the manufacture of medical instruments. One of the features for this class of steels is their corrosion resistance in river or tap water due to spontaneous passivation of stainless steels in these environments. Nevertheless, in practice, corrosion damage has been sometimes observed, the reasons for which cannot always be taken into account when designing stainless steel products [6-8]. Our recent studies have shown that even more 
corrosion-resistant austenitic steel 301 (X18H9) can be subject to pitting corrosion in river water [8]. In this case, pitting lesions often develop into through holes. Given the use of in medicine, such damage is completely unacceptable. It seems important to study the corrosion behavior of 301 type steels in a weakly mineralized aquatic environment and establish the conditions for pitting occurrence. First of all, this concerns the study of the ability to neutralize the effect of chloride ion as an initiator of pitting corrosion, using other constituents, for example, sulfate and carbonate ions.

The experiments have been carried out in model solutions simulating river or tap water. These solutions contained the anions $\left[\mathrm{Cl}^{-}\right],\left[\mathrm{SO}_{4}^{2-}\right],\left[\mathrm{HCO}_{3}^{-}\right]$. The concentration of the main anions was: chloride ion from $12.5 \mathrm{mg} / \mathrm{L}$ to $500 \mathrm{mg} / \mathrm{L}$, sulfate ion from $0 \mathrm{mg} / \mathrm{L}$ to $100 \mathrm{mg} / \mathrm{L}$ and hydrocarbonate ion from $0 \mathrm{mg} / \mathrm{L}$ to $100 \mathrm{mg} / \mathrm{L}$. Electrochemical measurements were performed on IPC-Micro potentiostat (Russia). Potentials are given relative to a standard hydrogen electrode. The sweep $(0.1 \mathrm{mV} / \mathrm{s})$ began from the potential $E_{0}$ established after a 10-minute exposure in the solution until the potential $E_{\mathrm{p}}$ at which a sharp increase of current associated with the pitting breakdown take place. After that, the sweep was reversed to determine the repassivation potential. In all of the listed model solutions, AISI 420 steel was in a spontaneous passive state. Values of the corrosion potential $E_{\mathrm{c}}$ were in the range from +50 to $+100 \mathrm{mV}$, and the corrosion rate was negligible (even a slight turbidity of the initially shiny surface is not noticeable after the exposure).

Firstly we investigated the possibility of pitting corrosion in the presence of the only chloride ions, as the main source of pitting corrosion. At all studied chloride ion concentrations the anodic polarization led to breakdown of the oxide film and the formation of pitting. Typical anodic polarization curves are shown in Figure 1.

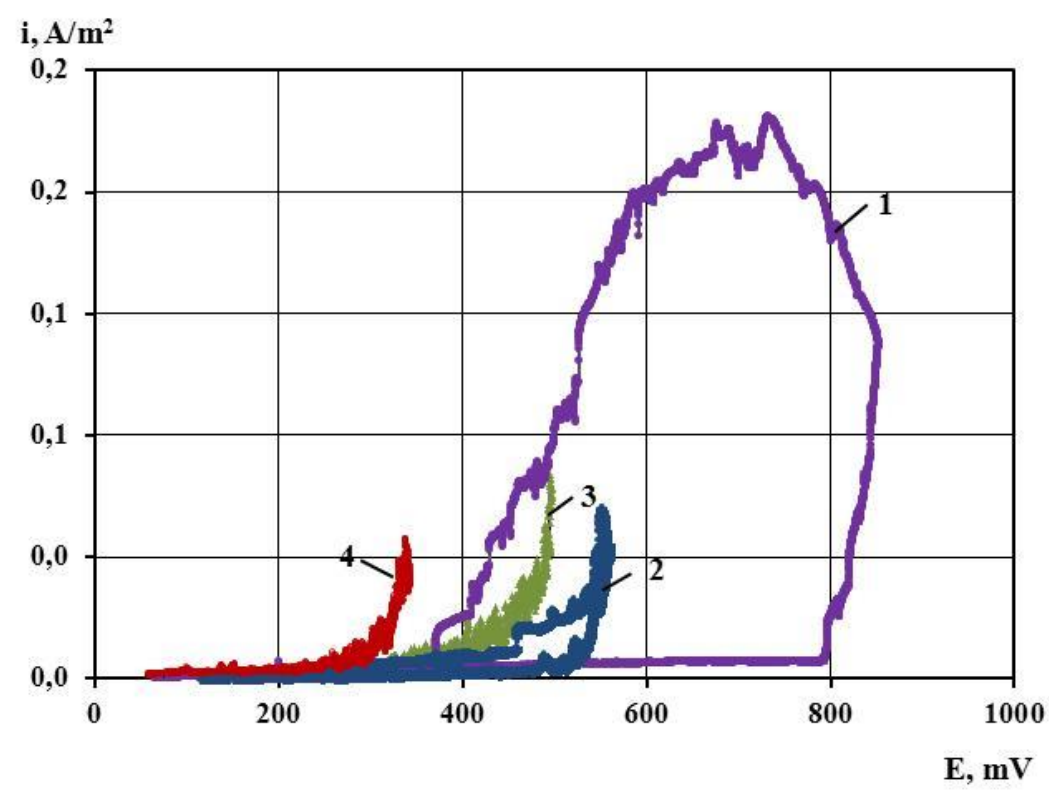

Figure 1. Potentiodynamic curves in a solution containing only $\left[\mathrm{Cl}^{-}\right]$ions at different concentrations: (1) $-12.5 \mathrm{mg} / \mathrm{L}$; (2) $-25.0 \mathrm{mg} / \mathrm{L}$; (3) $-50 \mathrm{mg} / \mathrm{L}$; (4) $-100 \mathrm{mg} / \mathrm{L}$. 


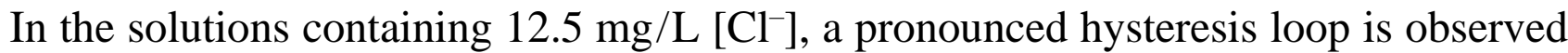
during the reverse sweep. With a chloride content of $25 \mathrm{mg} / \mathrm{L}$, hysteresis is poorly expressed, and at $50 \mathrm{mg} / \mathrm{L}$ and $100 \mathrm{mg} / \mathrm{L}$ it is completely absent. Both in the forward and reverse sweeps, significant current oscillations were observed. An increase in chloride concentration from $12.5 \mathrm{mg} / \mathrm{L}$ to $100 \mathrm{mg} / \mathrm{L}$ naturally leads to a decrease in the pitting potential. At the same time, the repassivation potential for all solutions, as a rule, was in the range of $+350 \ldots+450 \mathrm{mV}$. Given the poor reproducibility of the repassivation potential values, it can be fairly confidently stated that it is practically independent of chloride concentration. The dependence of the pitting potential vs. chloride ions concentration is well straightened in semilogarithmic coordinates (Figure 2, line 1).



Figure 2. The dependence of the pitting potential on the logarithm of the chloride ions concentration at the various amounts of sulfate ions addition: (1) - without $\left[\mathrm{SO}_{4}^{2-}\right]$,

(2) $-50 \mathrm{mg} / \mathrm{L}\left[\mathrm{SO}_{4}^{2-}\right],(3)-100 \mathrm{mg} / \mathrm{L}\left[\mathrm{SO}_{4}^{2-}\right]$.

Line (1) is described by the equation:

$$
E=1200-430 \cdot \log \left[\mathrm{Cl}^{-}\right] /\left[\mathrm{Cl}^{-}\right]_{0}
$$

Where $\left[\mathrm{Cl}^{-}\right]$is the chloride ions concentration in the solution $(\mathrm{mg} / \mathrm{L}) ;\left[\mathrm{Cl}^{-}\right]_{0}=1 \mathrm{mg} / \mathrm{L} ; E$ is the potential in $\mathrm{mV}$ (SHE). A fairly good agreement between the experimental points and the straight line describing them allows extrapolations to determine the conditions for the pitting occur. At the extrapolation with the logarithmic dependence (1) to the region of the free corrosion potential, it turns out that without additional polarization pitting is possible at a chloride ion concentration above $300 \mathrm{mg} / \mathrm{L}$. Considering that the pitting process is practically impossible when the anodic potentials achieves region of oxygen and/or chlorine depolarizing reactions, because the pitting potential can't shift spontaneously more positively due to the insufficiency of the anodic process that is in equilibrium with the cathodic one. Therefore, at such potentials area pitting corrosion is completely impossible and from the equation (1), taken into account the potential of oxygen reduction (about $+1000 \mathrm{mV}$ ), 
it is evident that "pitting immune region" starts at the chloride concentrations less than $1 \mathrm{mg} / \mathrm{L}$. In the concentration range from $1 \mathrm{mg} / \mathrm{L}$ to $300 \mathrm{mg} / \mathrm{L}$, pitting occurs during polarization: either from the external current source or internal from the additional cathodic depolarization process due to oxidizing agents entering the solution. One has to admit that it is getting incorrect to use this equation for higher chloride concentrations, as the behavior of the system becomes more complicated. To test the possibility of such extrapolation, we conducted studies on the pitting occurrence at high chloride concentrations of $250 \mathrm{mg} / \mathrm{L}$ and $500 \mathrm{mg} / \mathrm{L}$. It turned out that the logarithmic dependence is not observed above $\left[\mathrm{Cl}^{-}\right] 100 \mathrm{mg} / \mathrm{L}$. A further increase in the chloride ion concentration ceases to affect the pitting potential and it remains about $+340 \mathrm{mV}$. Thus, the linear dependence of the pitting potential vs. the logarithm of chloride concentration is observed only in a certain concentration range. The reasons for the violation on the logarithmic dependence can have both thermodynamic and kinetic explanations. If we accept that the basis of pitting is the chloride adsorption on the surface with its further penetration into the oxide, then we can assume that when the chloride concentration is exceeded, the degree of surface filling with it stabilizes or reaches a maximum for this alloy. This thermodynamic explanation requires additional research. As a kinetic explanation, we can assume the occurrence of a time delay for pitting. Those the duration of polarization from the corrosion potential to the potential of the oxide film at breakdown is the delay time. Therefore, when this potential is not much more positive than the corrosion potential, even a low sweep rate about $0.1 \mathrm{mV} / \mathrm{s}$ does not provide a clear definition of the pitting potential.

In support of this idea, an experiment was conducted in a solution with $500 \mathrm{mg} / \mathrm{L}$ of chloride, which is obviously more than is required for pitting during extrapolation to the corrosion potential. If we conduct anodic polarization from the corrosion potential at the sweep rate of $0.1 \mathrm{mV} / \mathrm{s}$, then the breakdown potential will be in the field of independence from the concentration $(+340 \mathrm{mV}$, see Figure 2). At the same time, if the alloy is simply maintained in this chloride solution, then a change in the corrosion potential can be observed (Figure 3). A gradual ennoblement of the potential occurs due to the gradual growth of an oxide passive film. After 48 minutes, there is a sharp drop and then restoration of potential, which can be explained by the emergence and healing of metastable pitting. After 2 hours, the final pitting breakdown of the alloy occurs and the potential decreases stepwise, reaching values $E_{\mathrm{c}}$ below the initial corrosion potential.

Typically, river and/or tap water contains a significant amount of bicarbonate. We investigated the possible inhibitory effect of bicarbonate on pitting. However, its effect in the chloride solution has not been found. Within the experimental error the pitting potential turned out to be the same both in a solution with a concentration of $100 \mathrm{mg} / \mathrm{L}$ chloride without bicarbonate and in a similar solution with the addition of $100 \mathrm{mg} / \mathrm{L}$ bicarbonate. A slight decrease in the breakdown potential in solutions with bicarbonate addition was detected in media in which sulfate was also added. However, this effect was so slight, that in general under experimental conditions the influence of bicarbonate on the pitting corrosion AISI 420 stainless ferritic steels can be considered insignificant. 


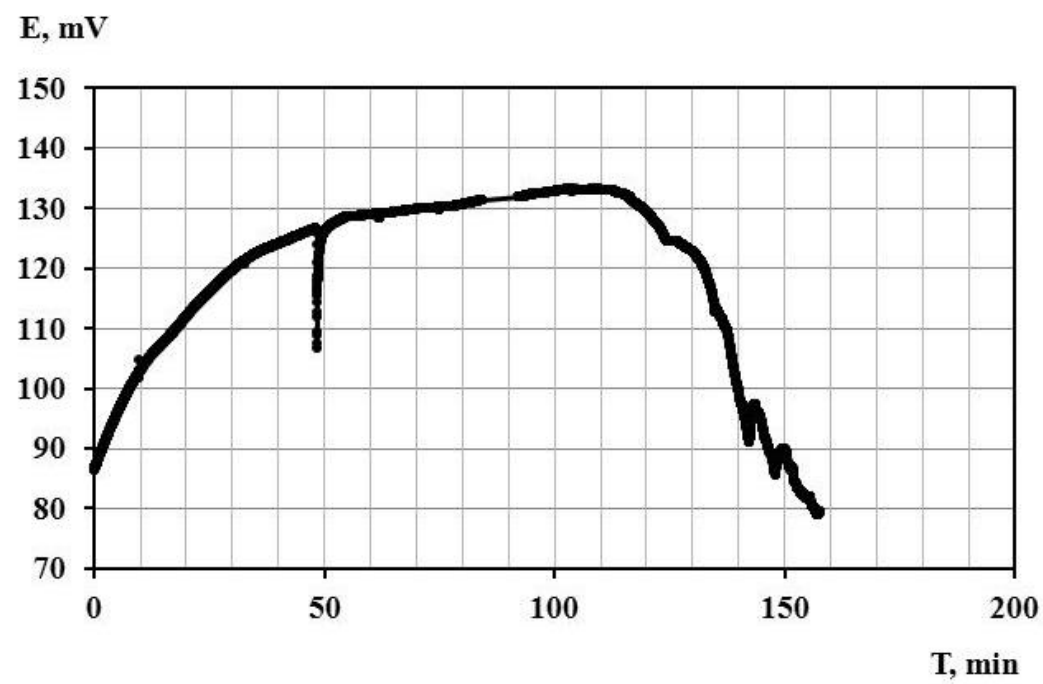

Figure 3. Potential dependence $v s$. time for a solution with chloride ion concentration of $500 \mathrm{mg} / \mathrm{L}$.

More interesting was the study of the inhibitory effect of sulfate on pitting corrosion of the stainless steels in chloride media, which has been discovered a long time ago. This issue has been studied in sufficient detail in the works of I.L. Rosenfeld and V.P. Maximchuk [5]. However, similar studies for small concentrations of chloride, corresponding to the composition of river water, are not available in the papers.

To study the effect, polarization curves were recorded in solutions containing chloride and sulfate ions in various ratios. The introduction of $\left[\mathrm{SO}_{4}^{2-}\right]$ into the solution with the same amount of $\left[\mathrm{Cl}^{-}\right]$shifts the pitting potential $E_{\mathrm{p}}$ to more positive values Figure 4.

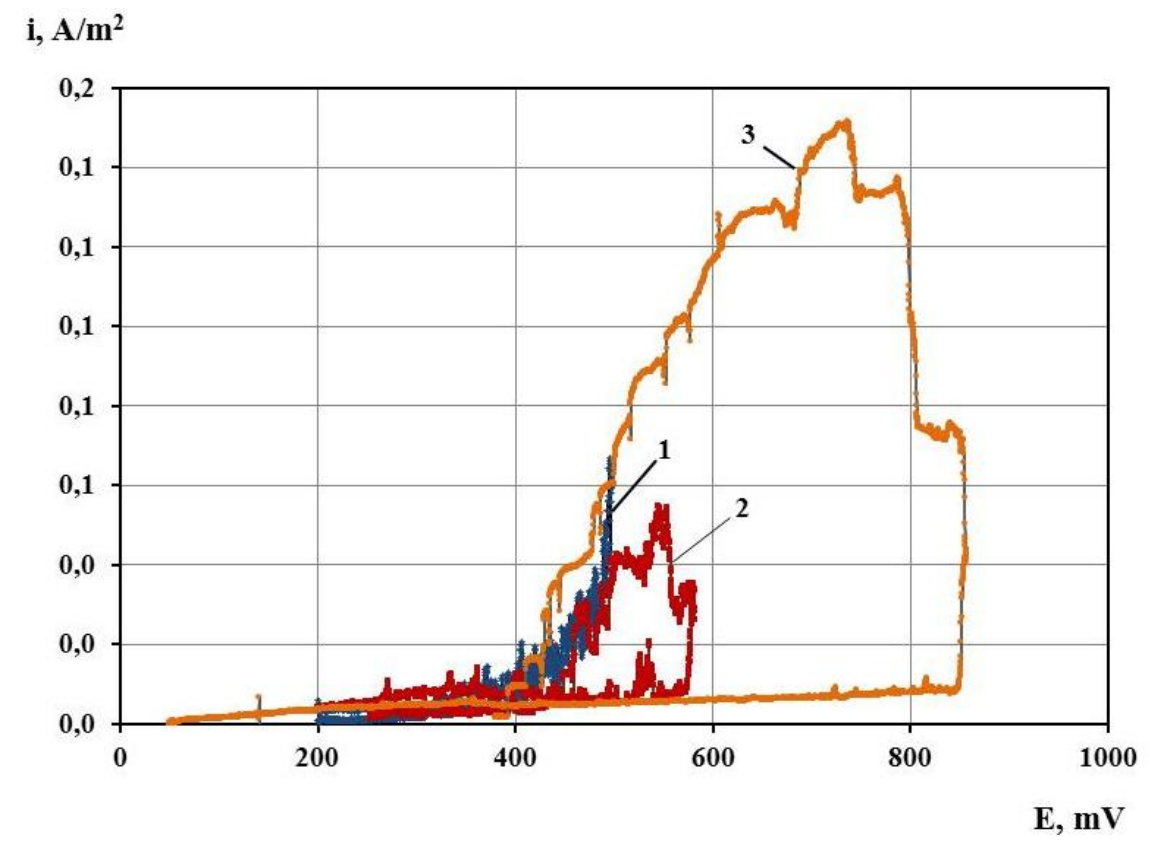

Figure 4. Effect of sulfate on the pitting potential in a solution with a concentration of $\left[\mathrm{Cl}^{-}\right]$ ions of $50 \mathrm{mg} / \mathrm{L}$ : (1)-without $\left[\mathrm{SO}_{4}^{2-}\right]$; (2) $-50 \mathrm{mg} / \mathrm{L}\left[\mathrm{SO}_{4}^{2-}\right]$; (3)-100 $\mathrm{mg} / \mathrm{L}\left[\mathrm{SO}_{4}^{2-}\right]$. 
The bias is the stronger, the lower the concentration of the initial chloride. It can be seen from Figure 4 that if hysteresis of the curve is practically not observed for pure chloride and the repassivation potential is close to the pitting potential, then with the introduction of sulfate and, especially, with an increase of its concentration in the solution, a clear hysteresis is observed. Moreover, the repassivation potential is practically independent of the sulfate concentration. Current fluctuations associated with the occurrence of metastable pits are observed during the forward direction sweep for solutions without sulfate or with low sulfate content. At $100 \mathrm{mg} / \mathrm{L}$ of sulfate concentration there are no current oscillations at the forward sweep, but they appear at the reverse direction sweep.

The dependence of the pitting potential on the concentration of chloride ions at a fixed sulfate content is also straightened in semilogarithmic coordinates (Figure 2). Extrapolation of the dependence to the potential range of the anodic release of chlorine and oxygen shows that for a solution, containing $50 \mathrm{mg} / \mathrm{L}$ of sulfate, the maximum safe concentration of chloride becomes $10 \mathrm{mg} / \mathrm{L}$ of chloride ion. For $100 \mathrm{mg} / \mathrm{L}$ of sulfate in the solution the concentration of chloride increases to $20 \mathrm{mg} / \mathrm{L}$, which is an order of magnitude more than for the case of pure chloride solution without any additives. A comparison of the pitting potential dependence on chloride ions concentration in the presence of $50 \mathrm{mg} / \mathrm{L}$ and $100 \mathrm{mg} / \mathrm{L}$ sulfate shows that an increase in the concentration of sulfate leads to a shift of the curve by $100 \mathrm{mV}$ towards greater resistance to pitting. It is possible to combine these dependencies into general, taking as argument the logarithm of $\left[\mathrm{Cl}^{-}\right] /\left[\mathrm{SO}_{4}^{2-}\right]$ ratio. The results of such a calculation are presented in Figure 5.

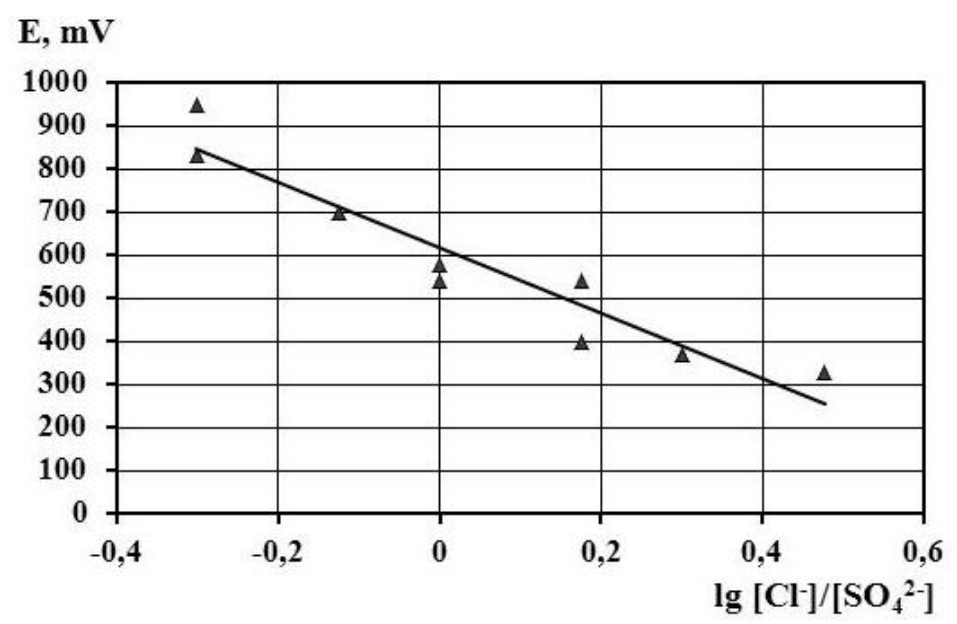

Figure 5. The dependence of the pitting potential on the ratio of ions concentrations $\left[\mathrm{Cl}^{-}\right] /\left[\mathrm{SO}_{4}^{2-}\right]$.

The experimental results fit perfectly to the equation:

$$
E=400-900 \cdot \lg \left[\mathrm{Cl}^{-}\right] /\left[\mathrm{SO}_{4}^{2-}\right]
$$

Where $\left[\mathrm{Cl}^{-}\right]$and $\left[\mathrm{SO}_{4}^{2-}\right]$ are the concentrations of chloride and sulfate ions $[\mathrm{mg} / \mathrm{L}] ; E$ is the potential $[\mathrm{mV}]$ (SHE). This dependence indicates the thermodynamic effect of the 
concentrations and can be considered as an adsorption equilibrium in the case of competing adsorption of chloride and sulfate on the oxide surface. Thus, it can be concluded that AISI 420 type stainless ferritic steel is susceptible to pitting corrosion in river and tap water environments with a sufficiently low chloride content. The presence of sulfate in the solution inhibits pitting corrosion, increasing the permissible concentration of chloride ions resulting into pitting formation. It should also be taken into account, especially for chloride concentrations of more than $100 \mathrm{mg} / \mathrm{L}$, that there is a certain time delay in the onset of pitting breakdown. The latter implies a time limit for the contact of stainless steel products with river or tap water.

\section{References}

1. E.A. Skrypnikova, S.A. Kaluzhina and L.E. Agafonova, Inhibition of copper pitting corrosion in alkaline sulphate media by benzotriazole at elevated temperatures, Int. J. Corros. Scale Inhib., 2014, 3, no. 1, 59-65. doi: 10.17675/2305-6894-2014-3-1-059-065

2. Yu.I. Kuznetsov, Progress in the science of corrosion inhibitors, Int. J. Corros. Scale Inhib., 2015, 4, no. 1, 15-34. doi: 10.17675/2305-6894-2015-4-1-015-034

3. M. Abdallah, I.A. Zaafarany, S. Abd El Wanees and R. Assi, Breakdown of passivity of nickel electrode in sulfuric acid and its inhibition by pyridinone derivatives using the galvanostatic polarization technique, Int. J. Corros. Scale Inhib., 2015, 4, no. 4, 338 352. doi: 10.17675/2305-6894-2015-4-4-4

4. V.I. Vigdorovich, L.E. Tsygankova, L.G. Knyazeva, A.V. Dorokhov, A.N. Dorokhova and M.V. Vigdorowitsch, Suppression of local corrosion of steel, brass and copper with IFKhAN-114 volatile inhibitor, Int. J. Corros. Scale Inhib., 2019, 8, no. 1, 42-49. doi: 10.17675/2305-6894-2019-8-1-4

5. I.L. Rosenfeld, Korroziya i Zashchita Metallov (Corrosion and metal protection), 1969, Moscow, Metallurgiya (in Russian).

6. A. Pfennig and A. Kranzmann, Local corrosion of martensitic stainless steels during exposure to saline aquifer water and $\mathrm{CO}_{2}$ environment, Int. J. Chem. Eng. Appl., 2018, 9, no. 1, 26-31. doi: 10.18178/ijcea.2018.9.1.694

7. M.A. Matvienko and E.N. Kovalyuk, Otsenka pittingostoikosti stalei 12X18H9 i 40X13 (Evaluation of pitting corrosion resistance of 12X18H9 and 40X13 steels), Vestnik IrGTU, Khimiya i Metallurgiya (Newsletter of the Angarsk State Technical University. Chemistry and Metallurgy), 2013, 81, no. 10, 224-228 (in Russian).

8. A.I. Scherbakov, I.V. Kasatkina, I.G. Korosteleva and L.P. Kornienko, Pittingovaya korroziya austenitnoi nerzhaveyushchei stali $12 \mathrm{X} 18 \mathrm{H} 9 \mathrm{v}$ slabomineralizovannoi (rechnoi) vode (Pitting corrosion of austenitic stainless steel $18 \mathrm{Cr}-9 \mathrm{Ni}$ in lowmineralized (river) water), Korroz.: Mater., Zashch. (Corrosion: Materials, Protection), 2018, 6, 32-34 (in Russian). 